\title{
Produção científica de bolsistas de produtividade: uma revisão de literatura nas bases de dados contempladas pelo Portal de Periódicos Capes
}

\author{
Guilherme Moreira Caetano Pinto \\ Mestre; Universidade Estadual de Ponta Grossa, Ponta Grossa, PR, Brasil; \\ prof.guilhermecaetano@gmail.com; ORCID: http://orcid.org/0000-0002-1971-6637 \\ Bruno Pedroso \\ Doutor; Universidade Estadual de Ponta Grossa, Ponta Grossa, PR, Brasil; \\ prof.brunopedroso@gmail.com; ORCID: http://orcid.org/0000-0002-7905-2393
}

\begin{abstract}
Resumo: O presente estudo analisa os artigos sobre a produção científica de bolsistas de produtividade do Conselho Nacional de Desenvolvimento Científico e Tecnológico (CNPq) nas bases de dados contempladas pelo Portal de Periódicos Capes até o ano de 2019. Dentre as bases pesquisadas estão: Web of Science, Scopus, Lilacs, Pubmed, SciELO, SportDiscus, tendo sido efetuada uma busca no próprio Portal de Periódicos da Capes, além da busca individual nas bases supracitadas. Para tal, foi realizada uma revisão sistemática de literatura. Foram selecionados 32 artigos para a análise do presente estudo. A análise dos artigos foi efetuada por meio dos seguintes indicadores: ano de publicação; periódico de publicação; autores; instituição dos autores; localidade da instituição dos autores; área de conhecimento abordada pelo artigo; idioma; classificação de corte; instrumento de coleta de dados do artigo; e subtema abordado pelo artigo. Os resultados da presente pesquisa indicam que: não foram encontrados estudos de coorte longitudinal; a maioria dos pesquisadores pertence a universidades da região sudeste; houve predomínio de publicações em periódicos pelos bolsistas de produtividade; em diversas pesquisas analisadas os bolsistas de produtividade foram mais produtivos que os nãobolsistas. Conclui-se que há a existência de algumas tendências, comuns em diversas áreas, acerca da produção científica de bolsistas de produtividade.
\end{abstract}

Palavras-chave: Produção científica. Bolsistas de produtividade. Revisão de literatura.

\section{Introdução}

A produção científica brasileira tem se desenvolvido nas diversas áreas do conhecimento, apresentando crescimento no número de artigos publicados (CAFÉ et al., 2011; COUTINHO et al., 2012; DIAS; MOITA, 2018; OLIVEIRA et al., 2014; PELLIZZON; CHIARI; GOULART, 2014). Esse crescimento é resultado de investimentos direcionados as pesquisas e a 
capacitação de recursos humanos, e impulsiona estudos relacionados a produção científica (CAFÉ et al., 2011; PELLIZZON; CHIARI; GOULART, 2014). Cabe destacar que a pesquisa científica no Brasil está diretamente ligada aos programas de pós-graduação Stricto Sensu e ocorre com o auxílio de agências de fomento como o Conselho Nacional de Desenvolvimento Científico e Tecnológico ( $\mathrm{CNPq})$, que concede bolsas de produtividade aos pesquisadores (COUTINHO et al., 2012; LETA; GLÄNZEL; THIJS, 2006).

Há três modalidades de bolsas de produtividade ofertadas no Brasil: a bolsa de produtividade em pesquisa (PQ), a bolsa de produtividade em desenvolvimento tecnológico e extensão inovadora (DT) e bolsa de produtividade em pesquisa Sênior (PQ-Sr) - até outrora, uma categoria das bolsas PQ. A modalidade PQ-Sr não apresenta divisão por categorias. Nas modalidades de bolsa PQ e DT há as categorias 1 e 2 . A categoria 2 é uma categoria inicial e tem vigência de 36 meses. A categoria 1 apresenta as subdivisões A, B, C e D, sendo o nível A o mais elevado com vigência de 60 meses. Por sua vez, as bolsas de nível 1B, 1C e 1D apresentam vigência de 48 meses. A bolsa PQ-Sr, cuja duração era vitalícia, recentemente passou a ser de 72 meses e se destina a pesquisadores líderes em sua área de atuação, após sucessivas renovações da bolsa de produtividade (PQ ou DT) no nível A ou B da categoria 1.

A bolsa de produtividade almeja incentivar pesquisadores e tem status de premiação para aqueles que apresentam atuação de destaque na sua área do conhecimento, sendo considerada promissora no desenvolvimento da ciência brasileira (KLEPA; PEDROSO, 2019; PICININ et al., 2013; SACCO et al., 2016; SANTOS; CÂNDIDO; KUPPENS, 2010).

Diante disto, sob justificativa de traçar tendências de produção e compreender como os pesquisadores podem obter esta honraria, são realizadas pesquisas para mapear a produção científica de bolsistas de produtividade (PELLIZZON; CHIARI; GOULART, 2014; PICININ et al., 2015).

Cabe ressaltar que há um crescimento de estudos cientométricos no Brasil (SCARPELLI et al., 2008). Isso traz avanços, mas dificulta a compreensão dos pesquisadores de todas as possibilidades de investigação e 
identificação das lacunas existentes. Neste sentido, o presente estudo justifica-se por oferecer um panorama sistematizado de pesquisas acerca da produção científica de bolsistas de produtividade, apresentando as peculiaridades e caminhos das pesquisas já realizadas, e as novas possibilidades de estudos sobre esta importante política de incentivo à ciência.

Através deste prisma, o presente estudo tem por objetivo analisar os artigos sobre a produção científica de bolsistas de produtividade do Conselho Nacional de Desenvolvimento Científico e Tecnológico (CNPq) nas bases de dados contempladas pelo Portal de Periódicos Capes publicados até o ano de 2019. Dentre as bases utilizadas estão: Web of Science, Scopus, Lilacs, Pubmed, SciELO, SportDiscus. Adicionalmente foi efetuada uma busca no próprio Portal de Periódicos Capes.

\section{Procedimentos metodológicos}

O presente estudo foi desenvolvido por meio de uma revisão sistemática com base na literatura de Costa e Zoltowski (2014) e Gomes e Caminha (2014). As bases de dados escolhidas para a presente revisão foram Web of Science, Scopus, Lilacs, Pubmed, SciELO, SportDiscus e Portal de Periódicos Capes. As palavras-chave utilizadas foram: "Produção Científica" AND "Bolsista de Produtividade" (Busca 1); "Produção Científica" AND "Bolsa de Produtividade em Pesquisa" (Busca 2); "Scientific Production" AND "Resercher's Grant" (Busca 3); "Scientific Production" AND “Grant Holders" (Busca 4); "Scientific Production" AND "Scholars Grant” (Busca 5); "Scientific Production" AND "fellowship of research productivity" (Busca 6).

A pesquisa nas bases de dados seguiu-se da seguinte forma:

a) Web of Science: 1) no site da Web of Science, "pesquisa básica" foi selecionada como a "pesquisa característica"; 2) no campo "pesquisa" foram inseridas em seis buscas distintas as palavras-chave do presente estudo; 3) o item "tópico" foi selecionado; 4) no campo "tempo estipulado" foi escolhida a opção "todos os anos 1945 a 2019”; 5) não foram efetuadas limitações de idioma, país e tipo de documento. 
b) Scopus: 1) no site da Scopus, "pesquisa de documentos" foi selecionada como a "pesquisa característica"; 2) no campo "pesquisa" foram inseridas em seis buscas distintas as palavras-chave do presente estudo; 3) no item "limit - published" foram escolhidas as opções "all years" to "2019"; 4) no item "document type" foi selecionada a opção "all"; 5) no item "acess type" foi selecionada a opção “all”; 6) não foram efetuadas limitações de idioma e país de publicação.

c) Lilacs: 1) no campo "refinar pesquisa" foi selecionada a opção "lilacs"; 2) no campo "pesquisar" foram inseridas em seis buscas distintas as palavras-chave do presente estudo; 3) no campo "no campo" foi selecionada a opção "palavras"; 4) a busca contemplou registros até o ano de "2019”; 5) não foram efetuadas limitações de idioma, país e tipo de documento. Não houve retorno de artigos.

d) Pubmed: 1) na página da base Pubmed foi selecionado o campo "advanced"; 2) no campo "pesquisar" foram inseridas em seis buscas distintas as palavras-chave do presente estudo; 3 ) no campo "builder" foi selecionada a opção "all fields"; 4) a busca contemplou registros até o ano de "2019"; 5) não foram efetuadas limitações de idioma, país e tipo de documento.

e) SciELO: 1) na página da base SciELO no campo "buscar artigos: entre uma ou mais palavras" foram inseridas em seis buscas distintas as palavras-chave do presente estudo; 2) no campo "ano de publicação" a busca contemplou registros até o ano de "2019”; 3) não foram efetuadas limitações de idioma, país e tipo de documento.

f) SportDiscus: 1) no campo "buscando: SportDiscus with full text" da página da referida base foi selecionada a opção "busca avançada"; 2) no campo "buscando: SportDiscus with full text" foram inseridas em seis buscas distintas as palavras-chave deste estudo; 3) no campo "modos de busca" foi selecionado o item "booleano/frase" e indicada a opção "aplicar assuntos equivalentes"; 4) no campo "limitar resultados", no item "data de publicação", limitou-se artigos 
publicados até o ano de 2019; 5) no campo "limitar resultados", nos itens "Idioma", "pais", "tipo de publicação", "subconjuntos da base de dados" e "tipo de documento" selecionou-se a opção "todos".

g) Portal de Periódicos da Capes: 1) na página da base Portal de Periódicos da Capes foi selecionado o campo "buscar assunto" e "busca avançada"; 2) no campo de pesquisa foram inseridas em seis buscas distintas as palavras-chave do presente estudo; 3) no campo "data de publicação" foi selecionada a opção "qualquer ano"; 4) no campo "tipo de material" foi selecionada a opção "todos os itens"; 5) no campo "idioma" foi selecionada a opção "qualquer idioma"; 6) no campo "data", no item "data final", foi selecionado o ano de "2019"; 7) não foram efetuadas limitações de país.

Cabe destacar que a busca foi efetuada em cada base de dados listada de forma isolada, ainda que o Portal de Periódicos Capes contemple as bases de dados Web of Science, Scopus, Lilacs, Pubmed, SciELO, SportDiscus. Esta metodologia foi adotada pois as bases de dados utilizam algoritmos de busca distintos. Desta forma, é possível que a busca a partir de um mesmo unitermo retorne diferentes resultados entre as bases de dados, sendo possível que um artigo que esteja presente em duas bases distintas apareça em apenas uma das bases pesquisadas. Ademais, constatou-se que alguns periódicos estavam presentes apenas em uma base de dados específica (a exemplo do Pubmed), e não no Portal de Periódicos Capes. Desta forma, utilizou-se a busca isolada em cada base e no Portal de Periódicos Capes, a fim de obter o maior número possível de artigos sobre a temática do presente estudo.

A busca foi realizada entre os meses janeiro e maio de 2020. O quadro 1 apresenta o número de artigos retornados em cada base de dados por palavrachave utilizada.

Quadro 1 - Número de resultados retornados por palavra-chave em cada base de dados.

\begin{tabular}{|l|c|c|c|c|c|c|}
\hline Base de Dados & Busca & Busca & Busca & Busca & Busca & Busca \\
\hline Scopus & $\mathbf{1}$ & $\mathbf{2}$ & $\mathbf{3}$ & $\mathbf{4}$ & $\mathbf{5}$ & $\mathbf{6}$ \\
\hline Web of Science & 0 & 0 & 0 & 4 & 1 & 0 \\
\hline SciELO & 0 & 0 & 0 & 2 & 0 & 0 \\
\hline
\end{tabular}



revisão de literatura nas bases de dados contempladas pelo Portal de Periódicos Capes

Guilherme Moreira Caetano Pinto, Bruno Pedroso

\begin{tabular}{|l|c|c|c|c|c|c|}
\hline Pubmed & 0 & 0 & 0 & 1 & 0 & 0 \\
\hline Lilacs de & 0 & 0 & 0 & 0 & 0 & 0 \\
\hline $\begin{array}{l}\text { Portal } \\
\text { Periódicos Capes }\end{array}$ & 37 & 19 & 0 & 13 & 0 & 1 \\
\hline SportDiscus & 5 & 25 & 0 & 23 & 161 & 483 \\
\hline
\end{tabular}

O fluxograma 1 apresenta o número de artigos duplicados e excluídos em cada base de dados.

Fluxograma 1 - Artigos selecionados para o presente estudo de acordo com cada base de dados.

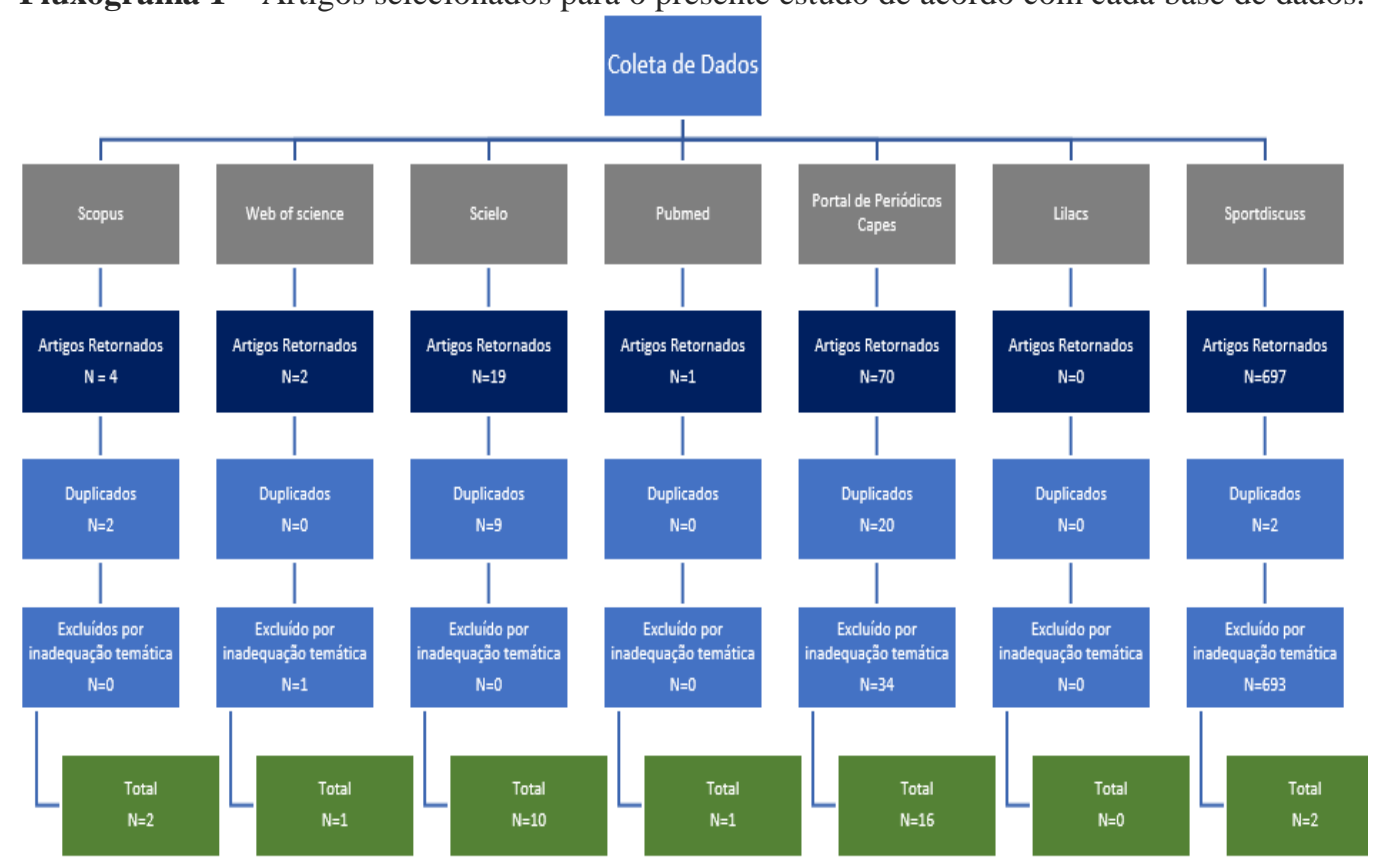

Fonte: Dados da Pesquisa (2020).

O número final de artigos analisados totalizou 32. Cabe destacar que o termo "duplicados" se refere a um mesmo artigo que apareceu em duas bases de dados distintas. Além disso, observa-se que a base de dados SportDiscus apresentou um elevado número inicial de artigos, mas resultou um número final de dois artigos. Este cenário pode ser justificado pelo algoritmo de busca da base de dados não conseguir efetuar um filtro específico pelas palavras-chave utilizadas. Sendo assim, é possível que a busca tenha considerado, além de artigos sobre bolsistas de produtividade, trabalhos publicados por autores que são bolsistas de produtividade, por se tratar de uma base da área do esporte.

A análise dos artigos foi efetuada por meio dos seguintes indicadores: ano de publicação; periódico de publicação; todos os autores do artigo; 
instituição dos autores; localidade da instituição dos autores; área de conhecimento abordada pelo artigo; idioma; classificação de coorte; instrumento de coleta de dados do artigo e subtema abordado pelo artigo, totalizando dez variáveis analisadas. Após a coleta de dados, os artigos foram planificados no software Microsoft Excel 2012. Posteriormente, efetuou-se uma análise dos dados considerando frequência e informações qualitativas que gerou a apresentação dos dados através de um gráfico e sete quadros.

\section{Resultados e discussões}

O gráfico 1 apresenta o ano de publicação dos artigos sobre a produção científica de bolsistas de produtividade analisados no presente estudo.

Gráfico 1 - Ano de publicação dos artigos sobre bolsistas de produtividade.

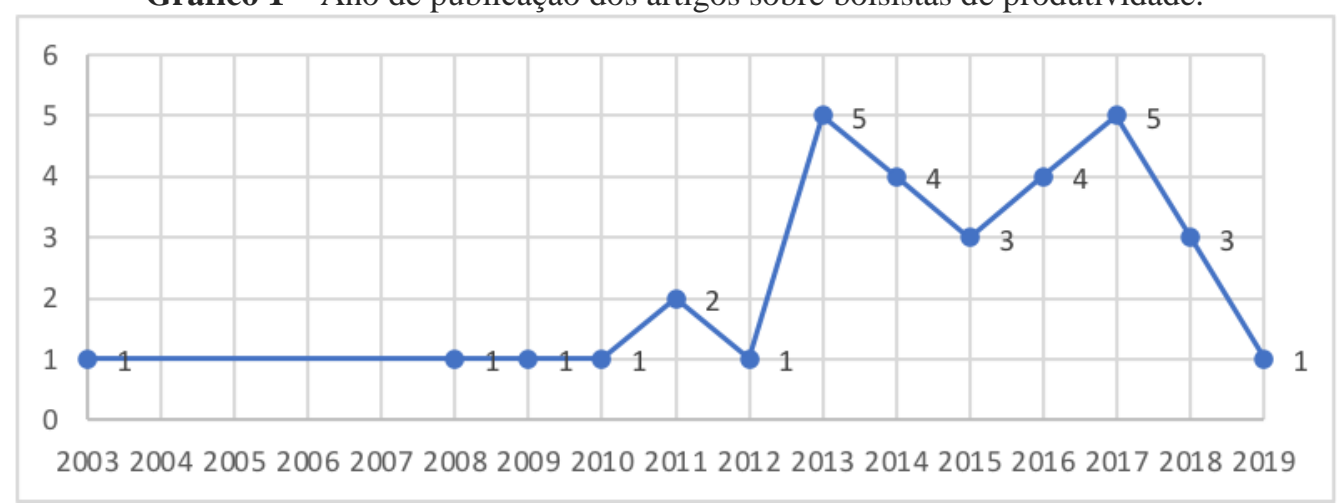

Fonte: Dados da Pesquisa (2020).

Observa-se que a primeira publicação ocorreu no ano de 2002. Ainda que tenham sido registrados artigos nos anos de 2003, 2008 e 2009, observa-se que o número de publicação de artigos cresceu a partir do ano de 2010. Isso indica um interesse recente pela temática, que ocorreu efetivamente no período da década de 2010-2019, com pico de cinco artigos publicados em 2013 e 2017. Em 2019 apenas um artigo foi publicado entre os artigos analisados nesta pesquisa. Não é possível afirmar se esta redução representa uma tendência de queda ou se é apenas uma pontualidade.

O crescimento do número de artigos publicados a partir de 2010 pode não ser uma exclusividade das pesquisas sobre bolsistas de produtividade. Através do decreto no 6.096 de 24 de abril de 2007 entrou em vigor o Programa 
de Apoio a Planos de Reestruturação e Expansão das Universidades Federais (REUNI), que tinha como objetivo principal aumentar o índice de acadêmicos na Educação Superior (BRASIL, 2007). Não obstante, entre 2000 e 2010 houve uma expansão do número de programas de doutorado. O número duplicou e atingiu o montante de 1.600 programas em 2010 (SOARES, 2018). Tais fatores podem ter contribuído para um crescimento de pesquisas publicadas no Brasil sobre diversas temáticas, não somente na área de abrangência dos bolsistas de produtividade.

O quadro 2 apresenta as revistas em que foram publicados os artigos sobre bolsistas de produtividade analisados no presente estudo.

Quadro 2 - Revistas em que foram publicados os trabalhos sobre bolsistas de produtividade analisados pelo presente estudo.

\begin{tabular}{|c|c|}
\hline Periódico de publicação & $\mathbf{n}$ \\
\hline Em Questão/Revista de Biblioteconomia e Comunicação da UFRGS & 2 \\
\hline Brazilian Journal of Physical Therapy & 2 \\
\hline Informação e Informação & 2 \\
\hline International Association for Management of Technology & 1 \\
\hline Brazilian Dental Journal & 1 \\
\hline Revista da Associação Médica Brasileira & 1 \\
\hline Revista Brasileira de Cineantropometria \& Desempenho Humano & 1 \\
\hline Revista de Nutrição & 1 \\
\hline Revista CEFAC & 1 \\
\hline Psicologia: Ciência e Profissão & 1 \\
\hline Tema & 1 \\
\hline Physis Revista de Saúde Coletiva & 1 \\
\hline Caderno de Saúde Pública & 1 \\
\hline Revista Paulista de Pediatria & 1 \\
\hline Revista Einstein & 1 \\
\hline Brazilian Journal of Nephrology & 1 \\
\hline Revista Brasileira de Educação Médica & 1 \\
\hline Interciencia: Revista de ciencia y tecnología de América & 1 \\
\hline Sociedade e Estado & 1 \\
\hline Estudos Feministas & 1 \\
\hline Revista Brasileira de Pós-graduação & 1 \\
\hline Revista de Administração contemporânea & 1 \\
\hline Anuário do Instituto de Geociências & 1 \\
\hline Brazilian Journal of Information Studies: Research Trends. & 1 \\
\hline Informação \& Sociedade: estudos & 1 \\
\hline Revista Brasileira de Finanças & 1 \\
\hline Revista Arthemis & 1 \\
\hline Bibliotecas: Anales de Investigácion & 1 \\
\hline
\end{tabular}




\section{Peerj \\ Fonte: Dados da Pesquisa (2020).}

Observa-se que 29 periódicos figuraram nos artigos analisados pelo presente estudo. As pesquisas sobre a produção científica de bolsistas de produtividade são realizadas por pesquisadores de áreas distintas, que avaliam suas respectivas áreas do conhecimento. Sendo assim, é comum que a publicação dos artigos ocorra em revistas da área em que os bolsistas foram avaliados, o que proporciona que várias revistas sejam listadas.

Em que pese o acima exposto verifica-se que as revistas Em Questão, Brazilian Journal of Physical Therapy e Informação e Informação obtiveram duas publicações dentro dos artigos analisados. No caso da revista Brazilian Journal of Physical Therapy, os artigos estavam relacionados a sua área específica (Fisioterapia). As revistas Em Questão e Informação e Informação, ambas com foco na Ciência da Informação, foram procuradas por pesquisadores de outras áreas, o que demonstra uma aproximação destes periódicos com o tema produção científica e bolsistas de produtividade.

O quadro 3 apresenta os autores que mais publicaram sobre a produção científica de bolsistas de produtividade entre os artigos analisados pela presente pesquisa. Foram considerados todos os autores que figuraram nos trabalhos investigados. Adicionalmente, são indicados os pesquisadores que apresentam cadastrado no Currículo Lattes, projeto ou linha de pesquisa atual, ou indicação a pesquisas na temática, na área destinada ao resumo do autor.

Quadro 3 - Autores dos trabalhos que foram publicados sobre Bolsistas de Produtividade analisados pelo presente estudo.

\begin{tabular}{|l|c|l|l|l|}
\hline \multicolumn{1}{|c|}{ Autor } & N & \multicolumn{2}{c|}{ Autores com uma publicação } \\
\hline Martelli, D.* & 6 & Sardenberg, F. & Valiente, L. & Mello, C.*(1C) \\
\hline $\begin{array}{l}\text { Martelli Júnior, } \\
\text { H. (2) }\end{array}$ & 6 & Gousand, D. & Vilanova, F. & Imasato, T.* \\
\hline Pedroso, B.** & 4 & Paiva, S. (1A) & Wendt, G. & Graelm, A. ** \\
\hline Oliveira, E. (2) & 4 & Pordeus, I. (1A) & De Sousa, D. & $\begin{array}{l}\text { Borenstein, D. } \\
(1 \mathrm{~A})\end{array}$ \\
\hline Picinin, C. & 3 & Grossi, D. B. (1B) & Koller, S. (1A) & Cândido, L.*** \\
\hline Quirino, I. & 3 & Fernandes, F.(1D) & Valle. M. (2) & Santos, N. \\
\hline Oliveira, M. & 3 & Ferreira, L. (1A) & Sakuray, F. & Rocha, J. (1A) \\
\hline Oliveira, E.F.* & 2 & Mello, M. (1A) & Santos, S. & Dias, T. *** \\
\hline
\end{tabular}




\begin{tabular}{|l|l|l|l|l|}
\hline Alves, B.* & 2 & Hallal, P. (1A) & Barata, R.*(1A) & Moita, G.* \\
\hline $\begin{array}{l}\text { Simões e Silva, } \\
\text { A. (1D) }\end{array}$ & 2 & Fonseca, S. (1A) & Goldbaum, M. & Da silva, C. \\
\hline Chiari, B. (1D) & 2 & Cantorani, J. & Pinheiro, S. & Mueller, S. *** \\
\hline Lima, L. & 2 & Sturmer, G. & Miranda, D. (1C) & $\begin{array}{l}\text { Silva, F. (1A) } \\
* * *\end{array}$ \\
\hline Carvalho, K. & 2 & Viero, C. & Leite, B. & Santos, A. (2) \\
\hline Menezes, V.*** & 2 & Silveira, M. & Klepa, T. & Tavares, A. \\
\hline $\begin{array}{l}\text { Oddone, N.* } \\
\text { Café, A. }\end{array}$ & 2 & Lukrafka, J. & $\begin{array}{l}\text { Pécoits-Filho, R. } \\
\text { (1A) }\end{array}$ & Parente, T. (2) \\
\hline Pilatti, L. (2) $*$ & 2 & Pinho, L. & Mendes, P.* & $\begin{array}{l}\text { Valentova, J. (2) } \\
* *\end{array}$ \\
\hline Colosimo, E. & 2 & Pellizzon, R.*** & Quirino Filho, S. & Da Silva, M. \\
\hline $\begin{array}{l}\text { Bufrem, L.** } \\
(1 D)\end{array}$ & 2 & Goulart, B. (2) & Scarpelli, A. C. & \\
\hline Sobral, N. ** & 2 & Sacco, A. & Gripp, G.* & \\
\hline Perlin, M.* & 2 & Testi, B. & Lima, B. *** & \\
\hline $\begin{array}{l}\text { Kovaleski, J. } \\
\text { (DT - 1D) }\end{array}$ & 2 & Mcelligott, A. & Oliveira, A.* & \\
\hline
\end{tabular}

Fonte: Dados da Pesquisa (2020).

* Pesquisadores com projeto de pesquisa atual direcionado a análise da produção científica

** Pesquisadores com linha de pesquisa direcionada a análise da produção científica.

*** Pesquisadores que indicam no resumo do autor pesquisa direcionada a análise da produção científica.

(1A), (1B), (1C), (1D), (2) indica os pesquisadores que detém bolsa PQ e seu respectivo nível. (DT 1D) indica pesquisadores que detém bolsa DT nível 1D

Dados coletados no Currículo Lattes dos pesquisadores até o dia 10 jan. 2020

Verifica-se que 84 autores figuraram no quadro 3. Os autores Martelli (6), Martelli Júnior (6), Pedroso (4) e Oliveira (4) são os pesquisadores com maior número de investigações nos artigos analisados. Destes, Martelli e Pedroso indicam em seu Currículo Lattes projeto ou linha de pesquisa relacionada a análise da produção científica, o que reforça que os referidos pesquisadores efetuam pesquisas continuadas sobre a temática.

Outro ponto de destaque é que 31 pesquisadores expostos no quadro 3 são bolsistas de produtividade em pesquisa ou desenvolvimento tecnológico. Dos que publicaram mais artigos, Martelli Júnior (6), Oliveira (4), Simões e Silva (2), Pilatti (2), Bufrem (2) e Kovaleski (2) detêm bolsa de produtividade no ano de execução da pesquisa. 
O número de pesquisadores com bolsa de produtividade é a menor parcela dentre os pesquisadores brasileiros. No entanto, o presente estudo demonstra que $36,90 \%$ dos 84 pesquisadores que publicaram artigos sobre a temática, detêm algum tipo de bolsa. Este número permite inferir que, em grande parte, as pesquisas sobre bolsistas são realizadas pelos próprios bolsistas de produtividade.

Ainda sobre os autores expostos no quadro 3, 30,95\% indicaram em seu Currículo Lattes a existência de linha, projeto de pesquisa ou informação no resumo do autor relacionada a análise da produção científica. Isto indica que ainda há um potencial de crescimento de pesquisas caso mais pesquisadores integrem grupos de pesquisa específicos à temática.

O Quadro 4 lista as instituições de vínculo dos autores que publicaram sobre a produção científica de bolsistas e seus respectivos estados.

Quadro 4 - Instituições de vínculo dos autores que publicaram trabalhos sobre bolsistas de produtividade analisados pelo presente estudo.

\begin{tabular}{|l|c|c|}
\hline \multicolumn{1}{|c|}{ Instituição } & N & UF \\
\hline Universidade Federal de Minas Gerais (UFMG) & 14 & MG \\
\hline Universidade de Montes Claros (UNIMONTES) & 8 & MG \\
\hline Universidade Federal do Rio Grande do Sul (UFRGS) & 8 & RS \\
\hline Universidade de São Paulo (USP) & 5 & SP \\
\hline $\begin{array}{l}\text { Universidade Federal de Ciências da Saúde de Porto Alegre } \\
\text { (UFCSPA) }\end{array}$ & 4 & RS \\
\hline Universidade Federal da Bahia (UFBA) & 3 & BA \\
\hline $\begin{array}{l}\text { Universidade Tecnológica Federal do Paraná (UTFPR Ponta } \\
\text { Grossa) }\end{array}$ & 3 & PR \\
\hline Universidade Federal de Santa Maria (UFSM) & 3 & RS \\
\hline Universidade Estadual de Ponta Grossa (UEPG) & 2 & PR \\
\hline Universidade Federal de São Paulo (UNIFESP) & 2 & SP \\
\hline University of London & 2 & ING \\
\hline Universidade Estadual de Campinas (UNICAMP) & 2 & SP \\
\hline Universidade Federal de Ouro Preto (UFOP) & 2 & MG \\
\hline $\begin{array}{l}\text { Centro Federal de Educação Tecnológica de Minas Gerais } \\
\text { (CEFET/MG) }\end{array}$ & 2 & MG \\
\hline Universidade de Brasília (UnB) & 2 & DF \\
\hline Universidade Federal de Pernambuco (UFPE) & 2 & PE \\
\hline Universidade Federal do Tocantins (UFT) & 2 & TO \\
\hline $\begin{array}{l}\text { Universidade Tecnológica Federal do Paraná (UTFPR } \\
\text { CURITIBA) }\end{array}$ & 1 & PR \\
\hline
\end{tabular}




\begin{tabular}{|l|c|c|}
\hline Universidade José do Rosário Vellano (UNIFENAS) & 1 & MG \\
\hline Pontifícia Universidade Católica de São Paulo (PUC/SP) & 1 & SP \\
\hline Universidade Federal de Pelotas (UFPel) & 1 & RS \\
\hline $\begin{array}{l}\text { Instituto Federal de Educação, Ciência e Tecnologia de São } \\
\text { Paulo, Câmpus Registro (IFSP - Câmpus Registro) }\end{array}$ & 1 & SP \\
\hline Universidade de Cruz Alta (UNICRUZ) & 1 & RS \\
\hline $\begin{array}{l}\text { Pontifícia Universidade Católica do Rio Grande do Sul } \\
\text { (PUC/RS) }\end{array}$ & 1 & RS \\
\hline Universidade Estadual de Londrina (UEL) & 1 & PR \\
\hline $\begin{array}{l}\text { Faculdade de Ciências Médicas da Santa Casa de São Paulo } \\
\text { (FCMSCSP) }\end{array}$ & 1 & SP \\
\hline Pontifícia Universidade Católica do Paraná (PUC/PR) & 1 & PR \\
\hline Universidade Paulista (UNIP) & 1 & SP \\
\hline $\begin{array}{l}\text { Conselho Nacional de Desenvolvimento Científico e } \\
\text { Tecnológico (CNPq) }\end{array}$ & 1 & DF \\
\hline Universidade Federal do Estado do Rio de Janeiro (UNIRIO) & 1 & RJ \\
\hline Universidade Federal do Rio de Janeiro (UFRJ) & 1 & RJ \\
\hline Universidade Federal Fluminense (UFF) & 1 & RJ \\
\hline Universidade Estadual Paulista Júlio Mesquita Filho (UNESP) & 1 & SP \\
\hline Universidade Federal de Santa Catarina (UFSC) & 1 & SC \\
\hline Universidade Federal do Pará (UFPA) & 1 & PA \\
\hline
\end{tabular}

Fonte: Dados da Pesquisa (2020).

Verifica-se que as instituições UFMG (14), UNIMONTES (8) E UFRGS (8) se destacam com o maior número de autores nas pesquisas analisadas. Considerando as regiões geográficas do Brasil, 16 instituições localizam-se na região Sudeste, 12 instituições na região Sul, duas instituições estão nas regiões Norte, Nordeste e Oeste, e uma instituição localiza-se na Inglaterra.

Este cenário justifica-se na premissa de que a produção científica no Brasil é superior em instituições de ensino superior com programas de pósgraduação Stricto Sensu, que estão localizadas nas regiões Sul e Sudeste do Brasil (CAPES, 2017; COUTINHO et al., 2012; DIAS; MOITA, 2018; GRIPP; TESTI, 2012; GUIMARÃES, 2011; KLEPA; PEDROSO, 2019).

Em relação ao idioma de publicação das pesquisas, 24 artigos $(75,00 \%)$ foram publicados no idioma português e oito no idioma inglês. Além disso, os 32 artigos publicados fizeram uso de um recorte transversal. A publicação de pesquisas no idioma português é natural, tendo em vista que as bolsas de produtividade são uma política pública brasileira utilizada para fomentar a 
pesquisa. Portanto, tendem a gerar inquietações na comunidade científica local (LETA; GLÄNZEL; THIJS, 2006; PICININ et al., 2015). Quanto ao recorte dos estudos, configura-se em uma limitação de pesquisas da área a inexistência de artigos de cunho longitudinal.

O quadro 5 apresenta as áreas do conhecimento que foram abordadas pelos artigos analisados no presente estudo. $\mathrm{O}$ item mais de uma área refere-se a artigos que investigaram mais de uma área do conhecimento.

Quadro 5 - Áreas do conhecimento abordadas pelos artigos analisados no presente estudo.

\begin{tabular}{|c|c|c|}
\hline Área & $\mathbf{N}$ & Referências \\
\hline $\begin{array}{l}\text { Ciências exatas e da } \\
\text { Terra }\end{array}$ & 3 & $\begin{array}{l}\text { Valle e Sakuray (2013); Lima (2013); Cândido, } \\
\text { Santos e Rocha (2016). }\end{array}$ \\
\hline Ciências Biológicas & 1 & Oliveira e Mello (2014). \\
\hline Engenharias & 2 & Picinin et al. (2013); Picinin et al. (2015). \\
\hline Ciências da Saúde & 13 & $\begin{array}{l}\text { Barata e Goldbaum (2003); Scarpelli et al. } \\
\text { (2008); Santos et al. (2009); Mendes et al. } \\
\text { (2010); Oliveira et al. (2011); Oliveira et al. } \\
\text { (2013); Sturmer et al. (2013); Oliveira et al. } \\
\text { (2014); Pellizzon, Chiari e Goulart (2014); } \\
\text { Chiari et al. (2016); Pedroso, Picinin e } \\
\text { Cantorani (2016); Pinho et al. (2017); Klepa e } \\
\text { Pedroso (2019). }\end{array}$ \\
\hline Ciências Agrárias & 0 & \\
\hline $\begin{array}{ll}\text { Ciências } & \text { Sociais } \\
\text { Aplicadas } & \end{array}$ & 4 & $\begin{array}{l}\text { Perlin e Santos (2015); Bufrem, Sobral e Silva } \\
\text { (2017); Imasato, Perlin e Borenstein (2017); } \\
\text { Bufrem } \text { et al. (2018); }\end{array}$ \\
\hline Ciências Humanas & 4 & $\begin{array}{l}\text { Café et al. (2011); Carvalho et al. (2013); } \\
\text { Sacco (2016); Alves e Oliveira (2018). }\end{array}$ \\
\hline $\begin{array}{l}\text { Linguística, Letras e } \\
\text { Artes }\end{array}$ & 0 & \\
\hline Mais de uma área & 5 & $\begin{array}{l}\text { Gripp e Testi (2012); Tavares e Parente (2015); } \\
\text { Silva e Mueller (2017); Valentova et al. } \\
\text { (2017); Dias e Moita (2018). }\end{array}$ \\
\hline
\end{tabular}

Fonte: Dados da Pesquisa (2020).

Verifica-se que houve um predomínio de pesquisas na área das Ciências da Saúde (40,62\%), seguida de pesquisas que envolviam mais de uma área do conhecimento e a área de Ciências Sociais Aplicadas (15,63\%). Por outro lado, destaca-se que não foram registradas pesquisas na área das Ciências Agrárias e Linguística, Letras e Artes. Dos artigos na área das Ciências da Saúde, destaca- 
se que $38,46 \%$ das publicações foram direcionadas a pesquisadores da área médica, demonstrando uma atenção destes pesquisadores à temática.

O Quadro 6 apresenta os instrumentos utilizados pelos pesquisadores para a coleta de dados nos artigos analisados pelo presente estudo.

Quadro 6 - Instrumentos utilizados para coleta de dados nos artigos sobre bolsistas de produtividade analisados no presente estudo.

\begin{tabular}{|c|c|c|}
\hline $\begin{array}{l}\text { Instrumento de } \\
\text { Coleta de dados }\end{array}$ & $\mathbf{N}$ & Referências \\
\hline $\begin{array}{l}\text { Plataforma Lattes } \\
\text { Currículo Lattes }\end{array}$ & 25 & $\begin{array}{l}\text { Barata e Goldbaum (2003); Scarpelli et al. } \\
\text { (2008); Santos et al. (2009); Mendes et al. } \\
\text { (2010); Café et al. (2011); Oliveira et al. } \\
\text { (2011); Gripp e Testi (2012); Carvalho et al. } \\
\text { (2013); Oliveira et al. (2013); Picinin et al. } \\
\text { (2013); Sturmer et al. (2013); Oliveira et al. } \\
\text { (2014); Pellizzon, Chiari e Goulart (2014); } \\
\text { Valle e Sakuray (2014); Picinin et al. (2015); } \\
\text { Tavares e Parente (2015); Cândido, Santos e } \\
\text { Rocha (2016); Pedroso, Picinin e Cantorani } \\
\text { (2016); Sacco et al. (2016); Imasato, Perlin e } \\
\text { Borenstein (2017); Pinho et al. (2017); } \\
\text { Valentova et al. (2017); Alves e Olivieira } \\
\text { (2018); Dias e Moita (2018); Klepa e Pedroso } \\
\text { (2019). }\end{array}$ \\
\hline $\begin{array}{l}\text { Plataforma Lattes/ } \\
\text { Brapci/Software } \\
\text { Vantagepoint }\end{array}$ & 2 & $\begin{array}{l}\text { Bufrem et al. (2018); Bufrem, Sobral e Silva } \\
\text { (2017); }\end{array}$ \\
\hline $\begin{array}{l}\text { Plataforma Lattes/ } \\
\text { Currículo Lattes e } \\
\text { Questionário }\end{array}$ & 1 & Silva e Mueller (2017). \\
\hline $\begin{array}{ll}\text { Entrevista } & \text { com } \\
\text { pesquisadores } & \end{array}$ & 1 & Lima (2013) \\
\hline $\begin{array}{l}\text { Guidelines para } \\
\text { concessão de bolsa }\end{array}$ & 1 & Chiari et al. (2016). \\
\hline Software Ucinet & 1 & Oliveira e Mello (2014). \\
\hline $\begin{array}{lrr}\text { Censos da } & \text { Educação } \\
\text { Superior } & \text { 1991-2012 } \\
\text { (INEP, 2013) } & \text { e dos } \\
\text { cursos } & \text { de } & \text { pós- } \\
\text { graduação stricto sensu } \\
\text { 2004-2012 } & \text { (CAPES, } \\
2013) & & \end{array}$ & 1 & Pelin e Santos (2015). \\
\hline
\end{tabular}

Fonte: Dados da Pesquisa (2020). 
Verifica-se que 87,5\% (25 estudos usaram apenas o Currículo Lattes, e três estudos utilizaram o currículo lattes e outra ferramenta em complemento) dos trabalhos analisados utilizaram a Plataforma Lattes/Currículo Lattes para investigar a produção científica dos bolsistas de produtividade. Tal cenário é previsível, visto que o Currículo Lattes, criado em 1999, tornou-se um padrão nacional e registra a produção científica dos pesquisadores do Brasil. Por ser considerado completo, confiável e abrangente, trata-se de um elemento indispensável para a avaliação do mérito acadêmico (PLATAFORMA LATTES, 2020).

No entanto, a utilização do Currículo Lattes também foi apontada como uma limitação em alguns artigos em virtude da qualidade das informações lá existentes. Isso ocorre porque o preenchimento fica a cargo do pesquisador e não há como os autores que estão efetuando a busca controlarem a qualidade das informações prestadas (MENDES et al., 2010; PINHO et al., 2017; SANTOS et al., 2009; SCARPELLI et al., 2008; STURMER et al., 2013).

Em conjunto com a Plataforma Lattes também foi utilizada a Base de Dados Referencial de Artigos Periódicos em Ciência da Informação (Brapci). Trata-se de um produto do projeto de pós-doutorado da pesquisadora Leilah Santiago Bufrem. A base de dados reúne 19.225 artigos publicados em 57 periódicos da área de Ciência da Informação e tem contribuído para estudos para melhoria na qualidade das produções na área (BRAPCI, 2020). O uso da Brapci foi associado ao software Vantagepoint, uma ferramenta para auxiliar na mineração de dados e facilitar a visualização das informações levantadas. Tais ferramentas se constituem como uma boa possibilidade metodológica para pesquisas da área.

Outras ferramentas foram utilizadas por pesquisas da área para a solução de problemas específicos. A guidelines para concessão de bolsa foi utilizada na área da Educação Física, Fisioterapia e Fonoaudiologia (CHIARI et al., 2016) e o censo da pós-graduação stricto sensu foi utilizada na área das finanças (PERLIN; SANTOS, 2015). A entrevista foi utilizada para investigar uma análise sobre os principais obstáculos enfrentados pelas mulheres para alcançar posições de destaque (LIMA, 2013). O software Ucinet, por sua vez, foi 
utilizado para construir redes de colaborações em pesquisas utilizadas pelos bolsistas de produtividade em um quadriênio específico (ALVES; OLIVEIRA, 2018).

O questionário também foi uma estratégia utilizada para coletar informações acerca do perfil e da produção científica dos pesquisadores. A aplicação do instrumento por correio eletrônico foi utilizada como uma forma de investigar o maior número de bolsistas possíveis (SILVA; MUELLER, 2017).

Um meio para reduzir eventuais problemas de subnotificação é efetuar a coleta após as datas de avaliação das agências de fomento e avaliações da Coordenação de Aperfeiçoamento de Pessoal de Nível Superior (Capes) dos programas de pós-graduação, visto que nestas datas há uma atenção maior por parte dos pesquisadores no preenchimento do currículo.

O Quadro 7 apresenta os subtemas abordados nos artigos sobre produção científica de bolsistas de produtividade analisados no presente estudo.

Quadro 7 - Subtemas abordadas nos artigos sobre bolsistas de produtividade analisados nos artigos do presente estudo.

\begin{tabular}{|l|c|l|}
\hline \multicolumn{1}{|c|}{ Tema } & n & \multicolumn{1}{|c|}{ Referência } \\
\hline $\begin{array}{l}\text { Análise do perfil e produção } \\
\text { científica de bolsistas de } \\
\text { produtividade }\end{array}$ & 20 & $\begin{array}{l}\text { Barata e Goldbaum (2003); Scarpelli et al. } \\
\text { (2008); Santos et al. (2009); Mendes et al. } \\
\text { (2010); Café et al. (2011); Oliveira et al. } \\
\text { (2011); Pécoits-Filho et al. (2011); } \\
\text { Carvalho et al. (2013); Oliveira et al. } \\
\text { (2013); Picinin et al. (2013); Sturmer et al. } \\
\text { (2013); Oliveira et al. (2014); Pellizzon, } \\
\text { Chiari e Goulart (2014); Perlin e Santos } \\
\text { (2015); Picinin et al. (2015); Cândido, } \\
\text { Santos e Rocha (2016); Sacco et al. (2016); } \\
\text { Pinho et al. (2017); Dias e Moita (2018); } \\
\text { Klepa e Pedroso (2019). }\end{array}$ \\
\hline $\begin{array}{l}\text { Análise dos critérios e } \\
\text { programas para concessão de } \\
\text { bolsa. }\end{array}$ & 3 & $\begin{array}{l}\text { Oliveira e Mello (2014); Valle e Sakuray } \\
\text { (2014); Chiari et al. (2016). }\end{array}$ \\
\hline $\begin{array}{l}\text { Análise dos mecanismos e } \\
\text { bases intelectuais para } \\
\text { publicação de artigos pelos } \\
\text { bolsistas de produtividade }\end{array}$ & 3 & $\begin{array}{l}\text { Bufrem, Sobral e Silva (2017); Bufrem et } \\
\text { al. (2018); Alves e Olivieira (2018). }\end{array}$ \\
\hline $\begin{array}{l}\text { Análise das dificuldades } \\
\text { encontradas por mulheres na } \\
\text { carreira acadêmica }\end{array}$ & 3 & $\begin{array}{l}\text { Lima (2013); Tavares e Parente (2015); } \\
\text { Valentova et al. (2017). }\end{array}$ \\
\hline
\end{tabular}




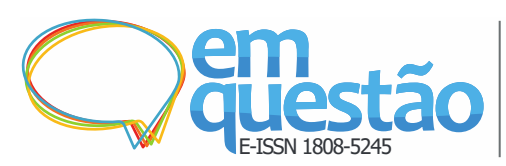

Produção científica de bolsistas de produtividade: uma revisão de literatura nas bases de dados contempladas

pelo Portal de Periódicos Capes

Guilherme Moreira Caetano Pinto, Bruno Pedroso

\begin{tabular}{|l|l|l|}
\hline $\begin{array}{l}\text { Análise da produção } \\
\text { científica em ensino superior }\end{array}$ & 2 & $\begin{array}{l}\text { Gripp e Testi (2012); Imasato, Perlin e } \\
\text { Borenstein (2017). }\end{array}$ \\
\hline $\begin{array}{l}\text { Análise dos periódicos em } \\
\text { que publicam os bolsistas de } \\
\text { produtividade }\end{array}$ & 1 & Pedroso, Picinin e Cantorani (2016). \\
\hline
\end{tabular}

Fonte: Dados da Pesquisa (2020).

Verifica-se que a maioria dos trabalhos almejavam efetuar uma análise do perfil e da produção científica de bolsistas de produtividade. $\mathrm{O}$ perfil dos bolsistas de produtividade referente ao sexo dos bolsistas será discutido junto com o subtema análise das dificuldades das mulheres na carreira acadêmica.

Estas pesquisas expõem que há um predomínio masculino no acesso às bolsas entre pesquisadores da região Norte. Além disso, apresentam que as mulheres ocupam os extratos menos elevados de bolsas de produtividade (1D e 2) (TAVARES; PARENTE, 2015). Essa diferença ocorre em diversas áreas, sendo maior na Engenharia e nas Ciências Exatas e da Terra e menor nas Ciências da Vida, Humanidades e Ciências Sociais Aplicadas (VALENTOVA et al., 2017).

O presente estudo demonstrou predomínio do número de mulheres no número de bolsistas de produtividade, sendo elas: Fisioterapia (período 2013), a Nutrição (período 2014-2015), a Fonoaudiologia (período 2010), a Psicologia (período 2014), Pediatria (período 2013-2016) e a Saúde Coletiva (período 2000-2002) (BARATA; GOUDBAUM, 2003; KLEPA; PEDROSO, 2019; PELLIZZON; CHIARI; GOULART, 2014; PINHO et al., 2017; SACCO et al., 2016; STURMER et al., 2013).

Por outro lado, em oito áreas houve um predomínio de homens na distribuição das bolsas, sendo elas: Odontologia (período 2001 a 2003), Hematologia e Oncologia (período 2006-2008), Pediatria (período 2006-2008), Nefrologia e Urologia (período 2006-2008), Geociências (período 2013), Sociologia (PQ1A no período 2011), na Medicina (2005-2007) e na Saúde Coletiva (período 2004-2006) (CAFÉ et al., 2011; CÂNDIDO; SANTOS; ROCHA, 2016; MENDES et al., 2010; OLIVEIRA et al., 2011; OLIVIERA et al., 2013; OLIVEIRA et al., 2014; SANTOS et al., 2009; SCARPELLI et al., 2008). 
Alguns fatores dificultam o acesso de mulheres no grupo de elite acadêmica, entre eles a inserção tardia de mulheres no campo da ciência e tecnologia, o androcentrismo na produção de ciência, a divulgação de resultados sexista, a maternidade e a necessidade de conciliar produção científica e família, a discriminação e a menor prevalência de mulheres em espaços de decisão (LETA, 2003; LIMA, 2013; MASCARENHAS, 2003; TAVARES; PARENTE, 2015). Nesse sentido, a literatura defende que são necessárias políticas e reformas para reduzir a desigualdade no campo científico brasileiro e em suas instituições (VALENTOVA et al., 2017).

No entanto observa-se que houve proximidade entre o número de áreas que apresentaram domínio masculino (8) e feminino (6) nos artigos analisados pelo presente estudo. Além disso, a representação de homens e mulheres se alterou ao longo do tempo na área da Saúde Coletiva - que no período 20002002 teve um leve predomínio feminino (51,30\%) e, no período de 2004-2006, um leve predomínio de homens (50,97\%) (BARATA; GOUDBAUM, 2003; SANTOS et al., 2009). Tendo em vista que em ambos os casos o predomínio foi pequeno, este cenário não evidencia uma grande alteração ao longo do tempo.

Já em relação ao caso da Pediatria no período de 2006 a 2008, os homens representavam 76,50\% dos bolsistas. Por sua vez, no período de 2013-2016 houve uma inversão e as mulheres passaram a ocupar 76,40\% das bolsas de produtividade.

Santos, Cândido e Kuppens (2010) observaram predomínio do sexo masculino no número de bolsas de produtividade em pesquisa na área da Química (período 2004 a 2009). Os autores observaram ainda que houve um aumento do número de bolsistas mulheres no ano de 2009 (32,80\%) em comparação ao ano de 2001 (29,00\%). O número também se elevou no Comitê Assessor de Química do CNPq. No entanto, houve redução no número de bolsistas mulheres no ano de 2009 (32,80\%) em comparação com o ano de 2008 (33,80\%). Além disso, as mulheres não figuravam em grande escala nas bolsas de maior nível, com números similares ao ano de 1999. Desta forma, foi possível evidenciar um aumento do número de mulheres nos pontos de decisão, 
como o Comitê Assessor de Química do CNPq, mas não foi possível descartar a limitação na ascensão feminina.

Os resultados da presente revisão também não destacam o cenário supracitado. No entanto, demonstram que não é possível uma generalização e que a inserção, mesmo que tardia, da mulher no campo da ciência (LETA, 2003; MASCARENHAS, 2003) pode estar amenizando seu efeito na divisão de bolsas por sexo dos pesquisadores em algumas áreas.

Os artigos demonstram ainda que há um amplo domínio de bolsistas de produtividade vinculados à instituições públicas localizadas na região Sudeste (CAFÉ et al., 2011; KLEPA; PEDROSO, 2019; MENDES et al., 2010; OLIVEIRA et al., 2011; OLIVEIRA et al., 2013; OLIVEIRA et al., 2014; PELLIZZON; CHIARI; GOULART, 2014; PINHO et al., 2017; SACCO et al., 2016; SANTOS et al., 2009; CÂNDIDO, SANTOS; ROCHA, 2016; SCARPELLI et al., 2008; STURMER et al., 2013).

A existência de um maior número de programas de pós-graduação Stricto Sensu nas regiões Sudeste e Sul (CAPES, 2017) justifica esse cenário, visto que a participação na pós-graduação parece ser um fator imperativo aos bolsistas (DIAS; MOITA, 2018; KLEPA; PEDROSO, 2019). Uma avaliação no sentido de estabelecer estratégias para expandir o número de programas de pósgraduação em outras regiões do Brasil pode reduzir esse cenário.

Em relação à produção científica dos bolsistas houve um indicativo de que um maior estrato da bolsa esteve relacionado a uma maior produção científica de artigos de alto impacto (JCR, A1 e A2) nas áreas da Engenharia da Produção (período 2007-2009), Odontologia (período 2001-2003), Psicologia (período 2014), Hematologia e Oncologia (período 2006-2008) (OLIVEIRA et al., 2014; PICININ et al., 2015; SACCO et al., 2016; SCARPELLI et al., 2008).

Os estudos mostraram ainda que os bolsistas de produtividade têm um elevado número de publicações de alto impacto, avaliada por $\mathrm{JCR}^{1}$, Qualis ${ }^{2}$ ou bases de dados (DIAS; MOITA, 2018; KLEPA; PEDROSO, 2019; OLIVEIRA et al., 2011; OLIVEIRA et al., 2013; OLIVEIRA et al., 2014; PELLIZZON; CHIARI; GOULART, 2014; PICININ et al., 2013; PICININ et al., 2015; SACCO et al., 2016; SANTOS et al., 2009; SCARPELLI et al., 2008). Este 
cenário confirma a perspectiva de que os bolsistas se configuram em uma elite acadêmica (CAFÉ et al., 2011). Cabe mencionar que até 2007 era adotado um modelo de Qualis distinto do atual e que se constatou nas publicações que investigaram tal período, que os bolsistas de produtividade publicaram em periódicos de estrato mais elevado para o modelo da época.

O tipo de produção científica predominante entre os bolsistas são os artigos de periódicos nas áreas da Engenharia da Produção (período 2007-2009), Hematologia/Oncologia (período 2006-2008), Psicologia (período 2014), Saúde Coletiva (período 2004-2006 e período 2000-2002), Pediatria (2013-2016), Medicina (período 2005-2007) e Geociências (período 2013) (BARATA; GOLDBAUM, 2003; CÂNDIDO; SANTOS; ROCHA, 2016; DIAS; MOITA, 2018; KLEPA; PEDROSO, 2019; MENDES et al., 2010; OLIVEIRA et al., 2014; PICININ et al., 2015; SANTOS et al., 2009).

A área da Sociologia diverge deste cenário e apresenta uma maior publicação de capítulo de livros (CAFÉ et al., 2011; CARVALHO et al., 2013). Historicamente, a área da Sociologia publica suas pesquisas na forma de livros. No entanto, houve uma migração para publicações em capítulos de livros, e um progresso nas publicações de artigos de periódicos (CAFÉ et al., 2011).

A tendência de uma preferência na exposição dos resultados via artigo é natural, visto a exigência de publicação de artigos de periódicos para a manutenção da bolsa. No entanto, fica evidente que algumas áreas têm características específicas que podem contribuir para um cenário divergente.

No que se refere às orientações, houve um maior número de iniciação científica (IC), seguido de mestrado e doutorado nas áreas da Hematologia e Oncologia (período 2006-2008), Fisioterapia (período 2010), Nefrologia e Urologia (período 2006-2008) e Geociências (período 2013) (OLIVEIRA et al., 2011; STURMER et al., 2013; OLIVEIRA et al., 2014; CÂNDIDO; SANTOS; ROCHA, 2016).

As orientações em nível de mestrado foram superiores, seguidas das orientações de doutorado e IC nas áreas da saúde coletiva (período 2004-2006) e Pediatria (período 2013-2016) (SANTOS et al., 2009; KLEPA; PEDROSO, 2019). Já nas áreas da Pediatria (período 2006-2008) e Medicina (período 2005- 
2007) as orientações de mestrado foram superiores, seguidas das orientações de IC e doutorado (MENDES et al., 2010; OLIVEIRA et al., 2013). Parece comum em todas as áreas a incidência de orientações em todos os níveis, desde a IC até o doutorado, o que foi exposto por Sturmer et al. (2013).

O segundo subtema que mais apareceu nas pesquisas investigadas foi a análise dos critérios de concessão de bolsa de produtividade. Uma modelagem dos critérios foi proposta para a área da matemática, evidenciando que artigos de Qualis A1 e A2 apresentaram maior importância à pontuação de pesquisadores. $\mathrm{O}$ modelo estabelece ainda que o pesquisador se torna apto a receber uma bolsa PQ2 quando publica pelo menos três artigos A1 nos últimos cinco anos (VALLE; SAKURAY, 2014). Os autores do estudo sugerem a execução de estudos semelhantes em outras áreas.

$\mathrm{Na}$ área da Educação Física, Fisioterapia e Fonoaudiologia foi demonstrado que os bolsistas de produtividade apresentam o índice $\mathrm{H}$ médio e escore médio de citações superior aos não-bolsistas (CHIARI et al., 2016). Estes resultados reforçam o exposto por Picinin et al. (2013) e Picinin et al. (2015) para a área da Engenharia de Produção, que indicam que os bolsistas contribuem para a produção científica nacional e são mais produtivos que pesquisadores não-bolsistas. Além disso, os autores apontam que há uma perspectiva de coerência entre os critérios de concessão de bolsa e os dados retornados.

No entanto, na Sociologia (período 2007-2009) houve a percepção de que a produção científica de bolsistas de produtividade não atende aos critérios estabelecidos (CARVALHO et al., 2013). Isto evidencia a importância de se observar as especificidades de cada área.

Sobre os critérios de concessão de bolsa Oliveira e Mello (2014) expõe que $81 \%$ dos pesquisadores da Biociências sugerem a adoção de novas métricas, tais como a internacionalização das pesquisas, a inovação em produtos ou processos, as atividades de gestão, além do potencial das pesquisas do autor se tornar uma referência para a área e/ou ter impacto efetivo na sociedade.

Nesse sentido, verifica-se que os critérios de concessão de bolsa chamam a atenção dos pesquisadores e, mesmo aparentando selecionar pesquisadores mais produtivos, são passíveis de críticas para sua melhoria. 
Outro ponto de destaque evidenciado pelo Quadro 5 refere-se à análise dos mecanismos e bases intelectuais para publicação de artigos por parte dos bolsistas de produtividade. As pesquisas na área da Ciência da Informação destacam a existência de redes de colaboração entre pesquisadores principalmente no período de 2010 a 2014, no qual houve uma maior interconexão entre os bolsistas de produtividade e avanços na internacionalização, o que fortaleceu a área (ALVES; OLIVEIRA, 2018).

Ainda para a área das Ciências da informação, foi observado que os bolsistas de produtividade utilizam em suas produções literatura internacional, publicam seus artigos em revistas de Qualis A em sua respectiva área e têm como temas principais a Tecnologias da Informação e Comunicação, a Biblioteca, a Indexação e a Bibliometria (BUFREM et al., 2017; BUFREM et al., 2018; SILVA; MUELLER, 2017). Chama a atenção o uso de literatura internacional por parte dos bolsistas de produtividade. Isto torna-se uma possibilidade de estudos em outras áreas, a fim de verificar se este cenário é uma tendência comum entre os bolsistas.

Os artigos sobre a análise da produção científica em ensino superior evidenciaram que os bolsistas de produtividade têm uma produção científica superior aos demais professores de ensino superior, tal como visto em Chiari et al. (2016). Este cenário é reforçado nas áreas da Administração, Engenharia Civil, Matemática, Filosofia, Psicologia (GRIPP; TESTI, 2012; IMASATO; PERLIN; BORENSTEIN, 2017). Ao que parece há uma tendência de que isso se replique em outras áreas do conhecimento e em outros períodos de análise.

Acerca do item análise dos periódicos em que publicam os bolsistas de produtividade, evidenciou-se para a área da Educação Física (período 20102012) que entre os 30 periódicos com mais publicações por parte dos bolsistas de produtividade, 15 periódicos tinham JCR e a maior parte apresentou extrato Qualis B2 ou superior (PEDROSO; PICININ; CANTORANI, 2016). O exposto indica uma tendência de publicações em revistas de maior impacto por pesquisadores da Educação Física e pode ser testado em outras áreas do conhecimento como sugerido por Sacco et al. (2016) e Pinho et al. (2017). 


\section{Considerações finais}

A presente pesquisa evidenciou que o número de artigos publicados nas bases de dados analisadas cresceu a partir do ano de 2011 e teve pico nos anos de 2013 e 2017, indicando que a temática é atual. Além disso, foi verificado que os 32 artigos analisados sobre a temática foram publicados em 29 revistas distintas, com destaque para as revistas Em Questão, Brazilian Journal of Physical Therapy e Informação e Informação.

Quanto aos autores observou-se que Martelli (6), Martelli Júnior (6), Pedroso (4) e Oliveira (4) apresentaram o maior número de publicações nos artigos analisados. É interessante ressaltar que apenas 30,95\% dos autores mencionaram em seu Currículo Lattes o projeto e/ou a linha de pesquisa relacionada a análise da produção científica, o que indica um potencial de crescimento de pesquisas sobre o tema em caso de expansão dos grupos de pesquisa.

A maior parte dos trabalhos utilizou a Plataforma Lattes e o Currículo Lattes como fonte de busca para analisar a produção científica de bolsistas de produtividade, o que parece se configurar em um padrão metodológico de pesquisas da área.

Não foram encontradas pesquisas longitudinais ou acompanhamentos por vários ciclos da produção dos bolsistas de produtividade e investigações nas áreas das Ciências Agrárias e Linguística, Letras e Artes. Tais aspectos se configuram em possibilidades de estudos futuros. Além destas, outras possibilidades são: pesquisas que identifiquem as revistas que os bolsistas mais publicam; pesquisas direcionadas a modelar critérios de concessão de bolsa nas diferentes áreas do conhecimento e pesquisas que aprofundem as diferenças na caracterização referente ao gênero dos bolsistas de produtividade.

A possibilidade de existência de artigos sobre bolsistas de produtividade não selecionados com as palavras-chave adotadas, bem como a não utilização de outras bases de dados e meios de publicação como livros, capítulos de livros, dissertações e teses representa uma limitação do presente estudo.

Por fim, conclui-se que foi possível observar, com base nas pesquisas analisadas, algumas tendências acerca da produção científica de bolsistas de 
produtividade em diversas áreas acadêmicas, principalmente no que se refere ao predomínio de publicação de artigos e a publicação de artigos de alto nível. Este cenário reforça a perspectiva de que o grupo representa uma elite acadêmica.

\section{Referências}

ALVES, Bruno Henrique; OLIVEIRA, Ely Francina Tannuri. Alguns conceitos da sociologia de Pierre Bourdieu relacionados com a análise de rede social. Informação \& Sociedade: Estudos, João Pessoa, v. 28, n. 3, p. 135-148, 2018.

BARATA, Rita Barradas; GOLDBAUM, Moisés. Perfil dos pesquisadores com bolsa de produtividade em pesquisa do $\mathrm{CNPq}$ da área de saúde coletiva.

Caderno de Saúde Pública, Rio de Janeiro, v. 19, n. 6, p. 1863-1876, 2003.

BASE DE DADOS REFERENCIAL DE ARTIGOS DE PERIÓDICOS EM CIÊNCIA DA INFORMAÇÃO (BRAPCI). Histórico da BRAPCI. Porto Alegre, 01 jan. 2010. Disponível em: https://brapci.inf.br/index.php/res/about. Acesso em: 01 jan. 2021.

BRASIL. Decreto n. 6.096, de 24 de abril de 2007. Institui o programa de Apoio a Planos de Reestruturação e Expansão das Universidades Federais - REUNI.

Diário Oficial da União: seção 1, Brasília, ano 186, p. 7, 25 abr. 2007.

BUFREM, Leilah Santiago et al. Temas relacionados à educação na produção científica periódica dos bolsistas de produtividade em pesquisa da área de Ciência da Informação no Brasil. Bibliotecas: Anales de Investigácion, Cuba, v. 18, n. 4, p. 179-192, 2018.

BUFREM, Leilah Santiago et al. Análise das influências intelectuais na produção científica da área de Ciência da Informação: um estudo sobre os bolsistas de produtividade em pesquisa (PQ-CNPq). Em Questão, Porto Alegre, v. 23, n. 5, p. 115-141, 2017.

CAFÉ, Anderson et al. A elite acadêmica da sociologia no Brasil e sua produção científica. Informação e Informação, Londrina, v. 21, n. 3, p. 19-39, 2011.

CÂNDIDO, Lucilene Faustina de Oliveida; SANTOS, Natasha Carvalho Ferreira; ROCHA, João Batista Teixeira. As Geociências do CNPq a partir de seus bolsistas de produtividade em pesquisa. Anuário do Instituto de Geociências, Brasília, v. 39, n. 1, p. 142-155, 2016.

CAPES. Relatório de Avaliação Quadrienal 2017 - Geográfia. Brasília, 2017.

CARVALHO, Kátia et al. Aspectos gerenciais da política científica brasileira: um olhar sobre a produção científica do campo da sociologia face aos critérios 
de avaliação do CNPq e da CAPES. Revista da Faculdade de Biblioteconomia e Comunicação da UFRGS, Porto Alegre, v. 19, n. 1, p. 187-212, 2013.

COSTA, Ângelo Brandelli; ZOLTOWSKI, Ana Paula Couto. Como escrever um artigo de revisão sistemática. In: S. H. Koller; M. C. P. de Paula Couto; J. V. Hohendorff (Org.). Manual de Produção Científica. Porto Alegre: Penso, 2014.

COUTINHO, Renato Xavier et al. Brazilian Scientific Production in Science Education. Scientometrics, Budapest, v. 92, n. 3, p. 697-710, 2012.

CHIARI, Brasília Maria et al. Research productivity grants: Physical Education, Physical Therapy, Speech Pathology, and Occupational Therapy. Brazilian Journal of Physical Therapy, São Carlos, v. 20, n. 1, p. 1-3, 2016.

DIAS, Thiago Magela Rodrigues; MOITA, Gray Farias. Um retrato da produção científica brasileira baseado em dados da plataforma lattes. Brazilian Journal of Information Studies: Research Trends, Marília, v. 12, n. 4, p. 62-74, 2018.

GARFIELD, Eugene. Citation indexes for science. A new dimension in documentation through association of ideas. International Journal of Epidemiology, v. 35, n. 5, p. 1123-1127, 2006.

GOMES, Isabelle Sena; CAMINHA, Iraquitan de Oliveira. Guia para estudos de revisão sistemática: uma opção metodológica para as Ciências do Movimento Humano. Movimento, Porto Alegre, v. 20, n. 1, p. 395-411, 2014.

GRIPP, Glícia; TESTI, Bruno Moreti. Trajetórias acadêmicas: um estudo comparado da carreira acadêmica em Minas Gerais. Sociedade e Estado, Brasília, v. 27, n. 1, p. 47-61, 2012.

GUIMARÃES, Reinaldo. O futuro da pós-graduação: avaliando a avaliação.

Revista Brasileira de Pós-Graduação, Brasília, v. 4, n. 8, p. 282-292, 2011.

IMASATO, Takeyoshi; PERLIN, Marcelo Scherer; BORENSTEIN, Dênis. Análise do Perfil dos Acadêmicos e de suas Publicações Científicas em Administração. Revista de Administração Contemporânea, Maringá, v. 21, n. 1, p. 62-83, 2017.

KLEPA, Thaís Carolina; PEDROSO, Bruno. Análise da produção técnicocientífica de bolsistas de produtividade do Conselho Nacional de Desenvolvimento Científico e Tecnológico (CNPq) na área da Pediatria. Revista Einstein, São Paulo, v. 18, n. 20, p. 1-6, 2019.

LETA, Jacqueline. As mulheres na ciência brasileira: crescimento, contrastes e um perfil de sucesso. Estudos avançados, São Paulo, v. 17, n. 49, p. 271-284, 2003. 
LETA, Jacqueline; GLÄNZEL, Wolfgang; THIJS, Bart. Science in Brazil. Part 2: Sectoral and institutional research profiles. Scientometrics, Budapest, v. 67, n. 2, p. 87-105, 2006.

LIMA, Betina Stefanello. O labirinto de cristal: as trajetórias das cientistas na Física. Estudos Feministas, Florianópolis, v. 21, n. 3, p. 883-903, 2013.

LINS, Marcos Pereira Estellita; PESSÔA, Leonardo Antônio Monteiro. Desafios da avaliação de publicações em periódicos: discutindo o novo Qualis da Área Engenharias III. Revista Brasileira de Pós-Graduação, Brasília, v. 7 , n. 12, p. 14-33, 2010.

MASCARENHAS, Maria Graça. Mulheres na ciência brasileira. Rio de Janeiro: Finep, 2003.

MENDES, Patrícia Helena Costa et al. Perfil dos Pesquisadores Bolsistas de Produtividade Científica em Medicina no CNPq, Brasil. Revista Brasileira de Educação Médica, Brasília, v. 34, n. 4, p. 535-541, 2010.

OLIVEIRA, Eduardo et al. Perfil e produção científica dos pesquisadores CNPq nas áreas de Nefrologia e Urologia. Brazilian Journal of Nephrology, São Paulo, v. 33, n. 1, p. 31-37, 2011.

OLIVEIRA, Maria Christina Lopes Araujo et al. Perfil e produção científica dos pesquisadores do Conselho Nacional de Desenvolvimento Científico e Tecnológico na área de Pediatria. Revista Paulista de Pediatria, São Paulo, v. 31, n. 3, p. 278-284, 2013.

OLIVEIRA, Maria Christina Lopes Araujo et al. Profile and scientific production of the Brazilian Council for Scientific and Technological Development $(\mathrm{CNPq})$ researchers in the field of Hematology/Oncology. Revista da Associação Médica Brasileira, São Paulo, v. 60, n. 6, p. 542-547, 2014.

OLIVEIRA, Alexandre Rodrigues; MELLO, Carlos Fernando. Indicadores para a avaliação da produtividade em pesquisa: a opinião dos pesquisadores que concorrem a bolsas do CNPq na área de Biociência. Revista Brasileira de PósGraduação, Brasília, v. 11, n. 25, p. 657-678, 2014.

PEDROSO, Bruno; PICININ, Claudia Tania; CANTORANI, José Roberto Herreira. Production of productivity scholarship researchers in Physical Education in the 20102012 triennium: "Top 30" journals with the highest number of publications. Revista Brasileira de Cineantropometria \& Desempenho Humano, Florianópolis, v. 18, n. 6, p. 731-736, 2016. PERLIN, Marcelo Scherer; SANTOS, André Alves Portela. Os pesquisadores, as publicações e os periódicos da área de Finanças no Brasil: Uma análise com base em currículos da plataforma Lattes. Revista Brasileira de Finanças, Rio de Janeiro, v. 13, n. 2, p. 162-199, 2015. 
PÉCOITS-FILHO, Eduardo Oliveira. Perfil e produção científica dos pesquisadores do CNPq nas áreas de Nefrologia e Urologia. Brazilian Journal of Nephrology, São Paulo, v. 33, n. 1, p. 31-37, 2011.

PELLIZZON, Rosely de Fátima; CHIARI, Brasília Maria; GOULART, Bárbara Niegia Garcia. Perfil dos pesquisadores com bolsa de produtividade em pesquisa do CNPq da área de fonoaudiologia. Revista CEFAC, São Paulo, v. 16, n. 5, p. 1520-1532, 2014.

PICININ, Claudia Tania et al. Critérios gerais para a concessão de bolsa produtividade no Brasil: um estudo na Engenharia de Produção. Interciencia: Revista de ciencia y tecnología de América, Caracas, v. 39, n. 11, p. 785-792, 2013.

PICININ, Claudia Tania et al. Analysis of the Technical-Scientific production of scholars grants CNPQ on Production Engineering in Brazil: Na Assessment of Year 2007-2009. International Association for Management of Technology, Miami, v. 24, p. 1795-1809, 2015.

PINHO, Lucinéia et al. Scientific production of researchers in the Nutrition field with productivity fellowships from the National Council for Scientific and Technological Development, Revista de Nutrição, Campinas, v. 30, n. 6, p. 681-690, 2017.

PLATAFORMA LATTES. Sobre a Plataforma Lattes. Brasília, 2020.

SACCO, Airi Macias et al. Perfil dos Bolsistas de Produtividade em Pesquisa do CNPq atuantes em Psicologia no Triênio 2012-2014. Psicologia: Ciência e Profissão, Brasília, v. 36, n. 2, p. 292-303, 2016.

SANTOS, Suelleng Maria Cunha et al. Perfil dos pesquisadores da Saúde Coletiva no Conselho Nacional de Desenvolvimento Científico e Tecnológico. Physis Revista de Saúde Coletiva, Rio de Janeiro, v. 19, n. 3, p. 761-775, 2009.

SANTOS, Natasha Carvalho Ferreira; CÂNDIDO, Lucilene Faustina de Oliveira; KUPPENS, Cristiano Lima. Produtividade em pesquisa do CNPq: Análise do perfil dos pesquisadores da Química. Química Nova, São Paulo, v. 33, n. 2, p. 489-495, 2010.

SCARPELLI, Ana Carolina et al. Academic Trajectories of Dental Researchers Receiving CNPq's Productivity Grants. Brazilian Dental Journal, Ribeirão Preto, v. 19, n. 3, p. 252-256, 2008.

SILVA, Cláudio Nei Nascimento; MUELLER, Suzana Pinheiro Machado. Prestígio e produção na ciência brasileira: os bolsistas de produtividade e a produtividade dos bolsistas. Informação \& Informação, Londrina, v. 22, n. 2. P. 340-355, 2017. 
SOARES, Paulo César. Contradições na pesquisa e pós-graduação no Brasil. Estudos Avançados, São Paulo, v. 32, n. 92, p. 289-313, 2018.

STREHL, Letícia. O fator de impacto do ISI e a avaliação da produção científica: aspectos conceituais e metodológicos. Ciência da informação, Brasília, v. 34, n. 1, p. 19-27, 2005.

STURMER, Giovani et al. Profile and scientific output analysis of physical therapy researchers with research productivity fellowship from the Brazilian National Council for Scientific and Technological Development. Brazilian Journal of Physical Therapy, São Carlos, v. 17, n. 1, p. 41-48, 2013.

TAVARES, Ariane; PARENTE, Temis Gomes. Gênero e carreira científica: um estudo a partir dos dados das Universidades Federais da região Norte do Brasil. Revista Arthemis, João Pessoa, v. 20, n. 1, p. 66-75, 2015.

VALENTOVA, Jaroslava et al. Underrepresentation of Women in the Senior Levels of Brazilian Science. PEERJ, San Diego, v. 5, n. 1, p. 1-1, 2017.

VALLE, Marcos Eduardo; SAKURAY, Fábio. On the Criteria for Receiving a Research Productivity Fellowship from the Brazilian National Council for Scientific and Technological Development in Mathematics. Tema, São Carlos, v. 15, n. 3, p. 237-248, 2014.

VITOR-COSTA, Marcelo; MAIA DA SILVA, Priscila; SORIANO, Jeane Barcelos. A avaliação da produtividade em pesquisa na Educação Física: reflexões sobre algumas limitações dos indicadores bibliométricos. Revista Brasileira de Educação Física e Esporte, São Paulo, v. 26, n. 4, p. 581-597, 2012.

\title{
Scientific production of grant holders: a literature review in databases indexed on Portal de Periódicos Capes
}

\begin{abstract}
This study analyzes the papers about the production scientific of grant holders in data base Portal de Periódicos Capes published up the year 2019. The data base used were: Web of Science, Scopus, Lilacs, Pubmed, Scielo, SportDiscus. Additionally, it was used the Portal de Periódicos da Capes data base. For this purpose, a sistematic literature review was conduced based on Costa and Zoltowski (2014) and Gomes and Caminha (2014) literature. 33 articles were selected of analysis in the present research. The analysis of the articles used the following indicadors: year of publication; journal; authors; author's university; state of author's university; knowledge área of the article; language: coorte classification; data collection instrument of article; and subtopic of the article. 10 variables were analysed. The results of the presente research indicate that: we not found research of longitudinal coorte; most Author's were from universities in the southeast region in many knowledge
\end{abstract}


areas; the grant holders published studies in articles form; the Grant holders were more productive than not grant holders in many knowledge areas. We concluded that, despite the existence of trends, it is necessary to the surveys identify the particularities of each area.

Keywords: Scientífic production. Grant's holders. Literature review.

Recebido: $22 / 07 / 2020$

Aceito: 19/01/2021

\section{Declaração de autoria}

Concepção e elaboração do estudo: Guilherme Moreira Caetano Pinto, Bruno Pedroso

Coleta de dados: Guilherme Moreira Caetano Pinto, Bruno Pedroso

Análise e interpretação de dados: Guilherme Moreira Caetano Pinto, Bruno Pedroso

Redação: Guilherme Moreira Caetano Pinto, Bruno Pedroso

Revisão crítica do manuscrito: Bruno Pedroso

\section{Como citar}

PINTO, Guilherme Moreira Caetano; PEDROSO, Bruno. Produção científica de bolsistas de produtividade: uma revisão de literatura nas bases de dados contempladas pelo Portal de Periódicos Capes. Em Questão, Porto Alegre, v. 27, n. 4, p 243-271, 2021. Doi: http://dx.doi.org/10.19132/1808-5245274.243271

\footnotetext{
1 Journal Citation Reports (JCR) apresenta os valores do fator de impacto do periódico, calculado pela divisão entre o número de citações de um artigo nos anos que antecedem a publicação do fator de impacto pelo número total de artigos publicados pela revista (GARFIELD, 2006).

${ }^{2}$ Qualis é utilizado como uma estratégia de planejamento e avaliação das pesquisas científicas, e atualmente classifica os periódicos de acordo com os extratos A1, A2, B1, B2, B3, B4, B5 e C. (LINS; PESSÔA, 2010; STREHL, 2005; VITOR-COSTA; DA SILVA; SORIANO, 2014).
} 